\title{
Calcium-based nanomaterials and their interrelation with chitosan: optimization for $\mathrm{pCRISPR}$ delivery
}

\author{
Navid Rabiee ${ }^{1}$. Mojtaba Bagherzadeh ${ }^{1}$ - Amir Mohammad Ghadiri ${ }^{1} \cdot$ Mahsa Kiani $^{1}$ - Sepideh Ahmadi ${ }^{2,3}$. \\ Vahid Jajarmi ${ }^{3,4}$. Yousef Fatahi ${ }^{5,6,7}$. Abdullah Aldhaher ${ }^{1} \cdot$ Mohammadreza Tahriri $^{8}$. Thomas J. Webster ${ }^{9}$. \\ Ebrahim Mostafavi ${ }^{9,10,11}$ [D
}

Received: 26 April 2021 / Accepted: 3 September 2021 / Published online: 22 September 2021

(c) Islamic Azad University 2021

\begin{abstract}
There have been numerous advancements in the early diagnosis, detection, and treatment of genetic diseases. In this regard, CRISPR technology is promising to treat some types of genetic issues. In this study, the relationship between calcium (due to its considerable physicochemical properties) and chitosan (as a natural linear polysaccharide) was investigated and optimized for pCRISPR delivery. To achieve this, different forms of calcium, such as calcium nanoparticles (CaNPs), calcium phosphate (CaP), a binary blend of calcium and chitosan including CaNPs/Chitosan and CaP/Chitosan, as well as their tertiary blend including CaNPs-CaP/Chitosan, were prepared via both routine and green procedures using Salvia hispanica to reduce toxicity and increase nanoparticle stability (with a yield of $85 \%$ ). Such materials were also applied to the human embryonic kidney (HEK-293) cell line for pCRISPR delivery. The results were optimized using different characterization techniques demonstrating acceptable binding with DNA (for both CaNPs/Chitosan and CaNPs-CaP/Chitosan) significantly enhancing green fluorescent protein (EGFP) (about 25\% for CaP/Chitosan and more than 14\% for CaNPs-CaP/Chitosan).
\end{abstract}

Keywords Gene delivery · Calcium-based non-viral vector · pCRISPR $\cdot$ Chitosan-based nanomaterials

Mojtaba Bagherzadeh

bagherzadeh@sharif.edu

Ebrahim Mostafavi

ebimsv@stanford.edu

1 Department of Chemistry, Sharif University of Technology, Tehran, Iran

2 Student Research Committee, Department of Medical Biotechnology, School of Advanced Technologies in Medicine, Shahid Beheshti University of Medical Sciences, Tehran, Iran

3 Department of Medical Biotechnology, School of Advanced Technologies in Medicine, Shahid Beheshti University of Medical Sciences, Tehran, Iran

4 Cellular and Molecular Biology Research Center, Shahid Beheshti University of Medical Sciences, Tehran, Iran

5 Department of Pharmaceutical Nanotechnology, Faculty of Pharmacy, Tehran University of Medical Sciences, Tehran 14155-6451, Iran
6 Faculty of Pharmacy, Nanotechnology Research Center, Tehran University of Medical Sciences, Tehran 14155-6451, Iran

7 Universal Scientific Education and Research Network (USERN), Tehran 15875-4413, Iran

8 Department of Engineering, Norfolk State University, Norfolk, VA 23504, USA

9 Department of Chemical Engineering, Northeastern University, Boston, MA 02115, USA

10 Stanford Cardiovascular Institute, Stanford University School of Medicine, Stanford, CA 94305, USA

11 Department of Medicine, Stanford University School of Medicine, Stanford, CA 94305, USA 


\section{Introduction}

Recently, gene editing and therapy have been considered a strategic and highly effective therapy for several genetic disorders and inherited diseases [1-4]. In this manner, smart gene delivery systems must have several featuresincluding acceptable biocompatibility, low cellular toxicity, and considerable transfection efficiency-for their transition from the laboratory to the clinics [5-9]. The technology known as CRISPR/Cas [clustered regularly as interspaced short palindromic repeats/CRISPR-associated protein (Cas)] can provide critical changes in the genome in a very precise manner. This technology is considered promising and highly achievable for developing a one-time cure for inherited diseases [10-14].

Generally, gene delivery systems are based on viral and non-viral vectors $[15,16]$. Recent publications have revealed significant transfection efficiency and low cellular toxicity for viral vectors $[17,18]$. However, based on immunology, there are several concerns regarding the immune response and other related issues when using viral vectors that may not present any defects for generations but can eventually cause structural problems in human molecular and cellular physiology [19-21]. From another perspective, viral vectors are very expensive, contradicting the mission of medical science and biotechnology to provide advanced techniques, facilities, and materials at minimal cost. Therefore, these viral vectors are not acceptable and cannot enter mass production [22-24].

In contrast, non-viral nano-vectors have gain the attentions of numerous scientists because of their low cost of synthesis and preparation, as well as numerous optimization capabilities, enabling scientists to prepare these vectors for prevention, early diagnosis, and even treatment (in different phases) of various diseases [25-30]. The term "efficacy-toxicity" presents a significant paradox in gene delivery systems. More precisely, considerable efficiency in the gene transfections usually increases the cytotoxicity, while low efficiency in the transfections deduces minimal cellular toxicity, acting as a serious obstacle for using nonviral gene delivery vectors. For these reasons, the synthesis and preparation of low-cost non-viral vectors with low cytotoxicity are of major importance [31].

A wide range of polymers have been researched for the transfection performance of and optimization process for gene delivery vehicles, consuming significant time and money. These polymers are often selected based on their molecular weight (MW), size, zeta potential, and other physicochemical parameters [32-34]. Until now, polyethylenimine (PEI) has been known as the gold standard among non-viral gene delivery vectors, and several studies revealed that the above-mentioned paradox is concerning for this polymer. In general, high MW PEI leads to higher transfection efficiency, but meanwhile demonstrates considerable cytotoxicity hindering its widespread use [35, 36]. Scientists have been trying to use PEI in gene delivery, as some research groups work on its auto-fluorescence and nano to microstructure with low transfection efficiency. Attempts have been made to functionalize these structures with PEI with the hope of reducing its concentration and, therefore, reducing its cytotoxicity; however, still no significant results have been obtained to date [37-39]. Similarly, other scholars have focused on different polymeric materials-including poly(2-(dimethylamino) ethyl methacrylate (PDMAEMA) (with an IC50 value of around $4 \mu \mathrm{g} / \mathrm{mL}$ for the polyplex based on PDMAEMA) [40], polyamidoamine (PAMAM) (with an IC50 value of more than $31 \mu \mathrm{g} / \mathrm{mL}$ for the polyplex based on PAMAM) $[41,42]$ and poly(1-lysine) (PLL) (with an IC50 value of more than $40 \mu \mathrm{g} / \mathrm{mL}$ for the polyplex based on PLL) [43, 44]_finding similar results in terms of molecular weight and cytotoxicity as well. These results have led to the use of high MW polymers to improve transfection efficiency, yet all suffer from enhanced cytotoxicity. Therefore, the use of polymers alone for gene delivery systems has been questioned.

In recent studies, it has been shown that instead of using compounds with a single functional group, it is better to use highly-branched and complex structures with different functional groups for gene delivery systems [45-49]. Highly-branched structures can crosslink different biological molecules through their three-dimensional (3D) structure, and their multiple terminal groups increase the chance of physical and chemical interactions with different molecules or biological compounds. In this manner, highly-branched poly ( $\beta$-amino esters) (HPAEs) have shown promising results compared to PDMAEMA, PEI, and PLL [50-52]. Of course, from the perspective of solving the ultimate goal, studies on these highly branched polymers (almost all of those cited previously) were not properly organized and departed from the original objective of developing cost-effective polymer synthesis methods, ease of polymer modification and optimization, as well as material accessibility for different types of patients $[3,53,54]$.

In the literature, some reports have used natural cationic polysaccharides containing glucosamine units, chitosan, for gene delivery systems showing interesting results [55-57]. Generally, this unacetylated derivative polysaccharide can form stable complexes in the form of polyelectrolytes with DNA. In addition, chitosan at sizes smaller than $90 \mathrm{~nm}$ can form a homogenous complex and condense DNA very effectively [58-60]. Along this line, different nanoparticles have been investigated for various medical applications and certainly for gene transfection efficiency [61-63]. Among them, divalent metal cations including $\mathrm{Mg}^{2+}, \mathrm{Ca}^{2+}, \mathrm{Ba}^{2+}$, 
and $\mathrm{Mn}^{2+}$ are able to form meta-stable ionic complexes with DNA through helical phosphates [64-66]. In addition, some studies revealed that calcium phosphate $(\mathrm{CaP})$ could form stable complexes with the backbone of the nucleic acids and impart some stabilizing functions to the specified DNA structure $[67,68]$. In the next stage, the stable complexes are carried through ion channels across cell membranes to mediate endocytosis, which leads to DNA intracellular distribution internalized via CaP. However, the gene transfection efficiency of these carriers was at very low percentages (almost below 15\%) due to the rapid degradation of most of the endocytosed DNA and cytosol excreted, as well as a negligible fraction of the remaining exogenous DNA, which is vital for gene transfection and leads to poor transfection efficiency. Although $\mathrm{CaP}$ is considered as a simple, cost-effective, and efficient gene delivery system for in vitro transfection, it has limitations for in vivo use, including easy degradation after delivery of the genetic materials [69-71].

Taking all of the above into account, in this study, we investigated both the calcium nanoparticle and calcium phosphate effect on the transfection efficiency of pCRISPR, and further determined the cytotoxicity of these nanoparticles to a model HEK-293 cell line. Additionally, the effect of the green synthesized calcium nanoparticles (CaNPs) (using Salvia hispanica) on gene delivery was evaluated (Fig. 1).

\section{Methods}

\section{Preparation of CaNPs-chitosan}

Briefly, a homogeneous chitosan solution was prepared by adding $50 \mathrm{mg}$ of chitosan powder into $7 \mathrm{~mL}$ deionized water. Then the resultant solution was sonicated for $30 \mathrm{~min}$ (with the assistance of a probe sonic; $40 \mathrm{kHz}$ ). In the next step, $6 \mathrm{mg}$ of the green synthesized CaNPs was added to the solution, and the $\mathrm{pH}$ value was adjusted to 11 . The resultant suspension was then heated in an oven at $60^{\circ} \mathrm{C}$ for $3 \mathrm{~h}$, forming a homogenous hydrogel. The synthesized nanomaterial was

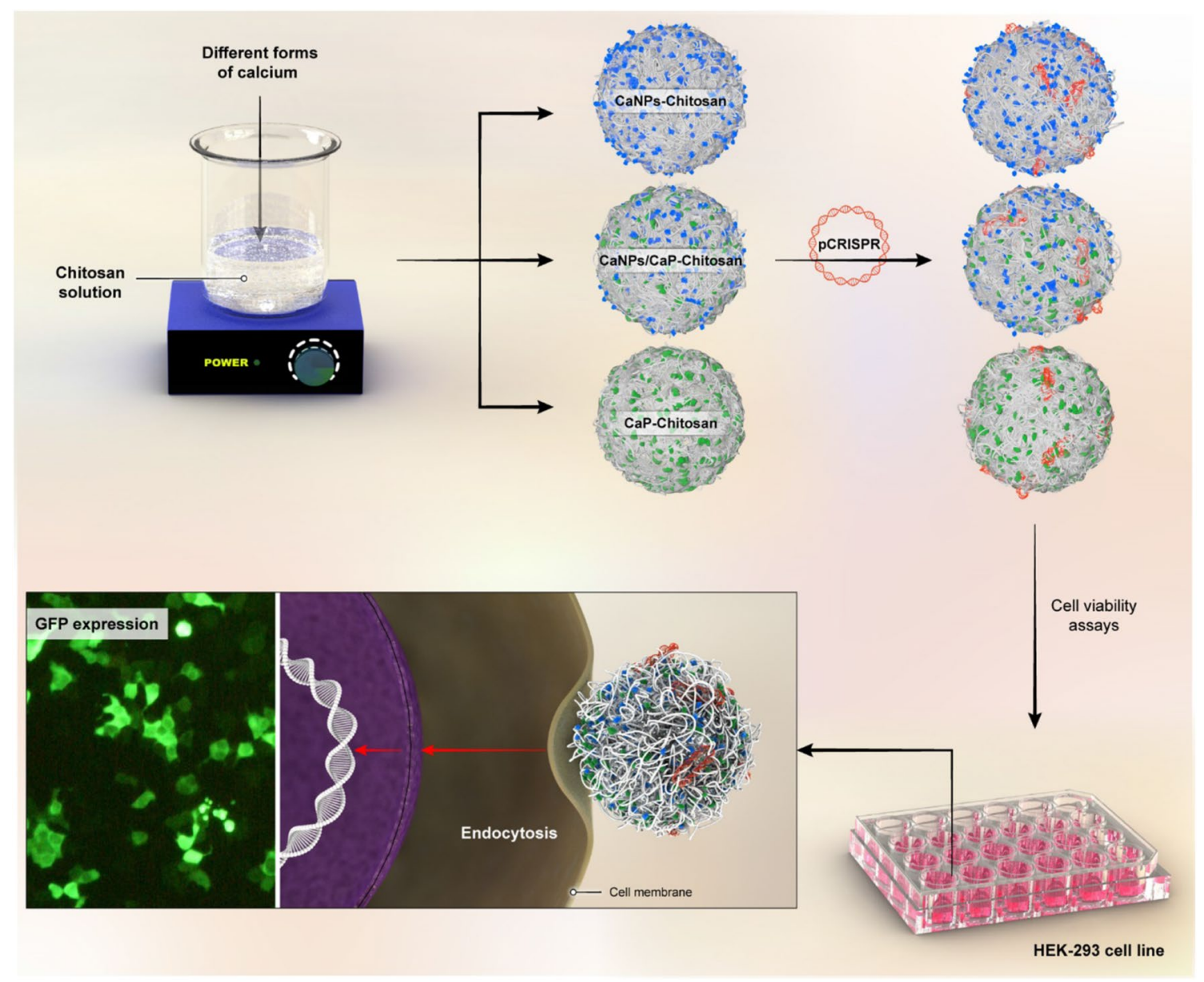

Fig. 1 A schematic illustration of the synthesis of CaNPs, CaP and their combination with chitosan and pCRISPR formation on the surface of the nanomaterials for gene delivery and transfection along with its possible influence on the HEK-293 cell line 
exposed to UV irradiation $(280 \mathrm{~nm})$ for about half an hour for sterilization before any biological assays.

\section{Preparation of CaP-chitosan}

For $\mathrm{Ca}-\mathrm{P}-\mathrm{Chitosan}$ preparation, a homogeneous chitosan solution was prepared by adding $85 \mathrm{mg}$ of the chitosan powder into $11 \mathrm{~mL}$ of deionized water (DI), with the final solution sonicated for about $42 \mathrm{~min}$ (with the assistance of a sonic probe; $40 \mathrm{kHz}$ ). In the next step, $12 \mathrm{mg}$ of the synthesized $\mathrm{CaP}$ was added to the solution, and the $\mathrm{pH}$ value was adjusted to 11 . The prepared suspension was then heated in an oven at $60{ }^{\circ} \mathrm{C}$ for $3 \mathrm{~h}$, forming a homogenous hydrogel. The synthesized samples were exposed to UV irradiation for about half an hour for sterilization before any biological assays.

\section{Preparation of CaNPs and CaP-Chitosan}

In this step, the protocol followed was similar to the one mentioned above. After the preparation of the homogenous chitosan solution, both CaNPs and CaP were added to the solution at an equivalent molar ratio, and the final $\mathrm{pH}$ was adjusted to 11 . The prepared suspension was heated in an oven at $60{ }^{\circ} \mathrm{C}$ for $3 \mathrm{~h}$, forming a homogenous hydrogel.

\section{Results}

\section{FE-SEM observations}

Based on the literature, the synthesized CaNPs should have a semi-spherical morphology with partial hexagonal structures $[72,73]$. In this study, both of these structures were obtained using a green CaNP synthesis method. However, due to the use of a plant in this synthesis method, the morphology was slightly unclear compared to published articles that did not use plants for synthesis. However, the spherical nature of the nanoparticles was quite clear in this study. Also, a small amount of residue from the plant can cause aggregation [74, 75], as evident in the reported images.

In the present work, the aim was to synthesize nanoparticles and nanomaterials with very low cytotoxicity, and therefore the plant was used. According to recent studies $[76,77]$, the general morphology of the nanosystem did not have a major impact on the gene delivery process; therefore, we assumed that the green synthesized nanoparticles and
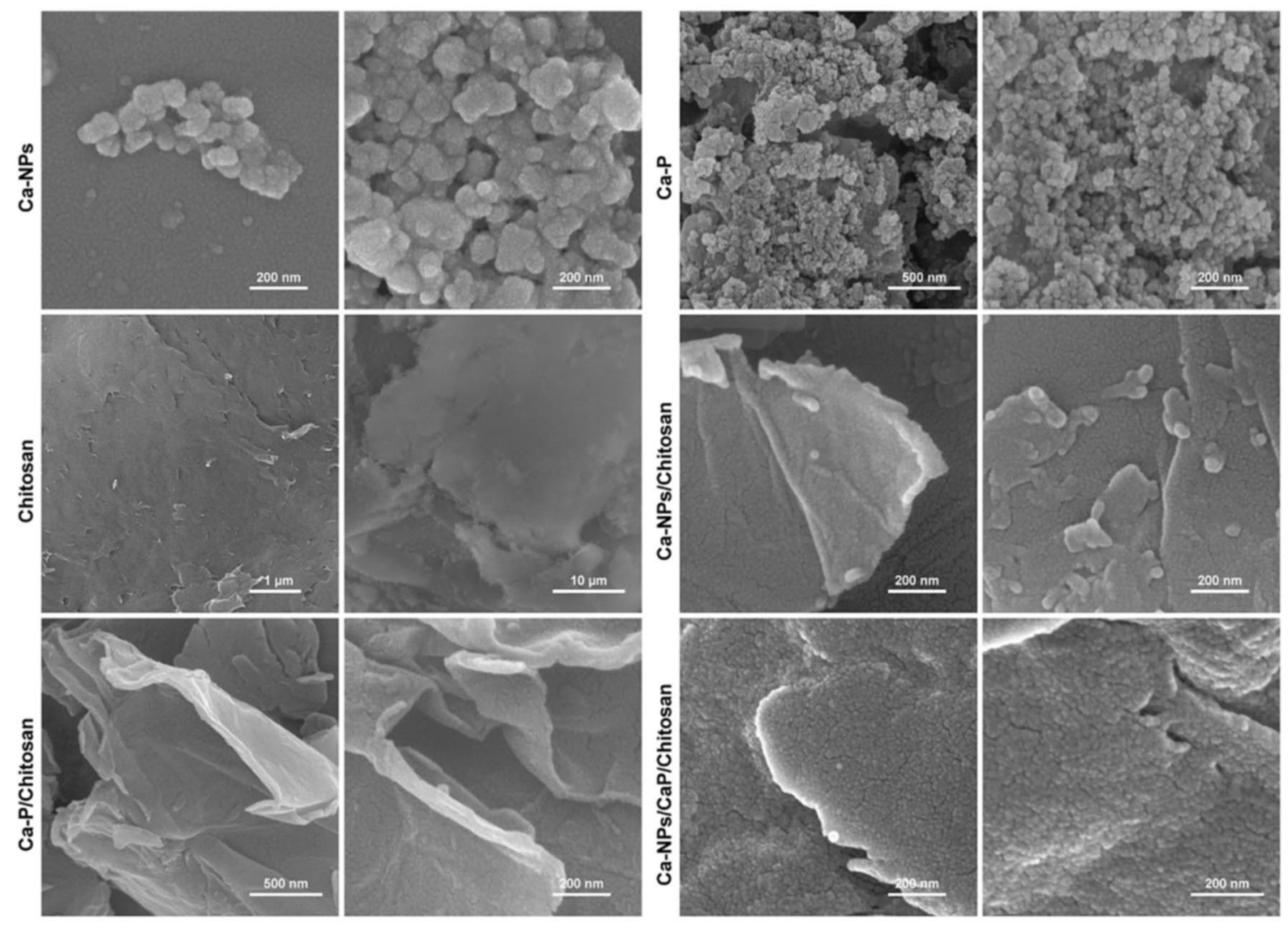

Fig. 2 FESEM images of the synthesized nanomaterials 
nanomaterials in this study were acceptable for gene delivery applications. The FE-SEM of CaP (Fig. 2) showed that the synthesized $\mathrm{CaP}$ were spherical with an occasional clustering morphology, which is also an acceptable morphology agreeing with literature $[78,79]$. In addition, chitosan has its own structural fingerprint [80-82] and the synthesized nanomaterials containing chitosan showed a clear non-flat and intertwined surface (Fig. 2). After adding chitosan, the FESEM images showed an almost homogenous and fullycovered nanostructure with chitosan, which could help the genetic material and other types of biomolecules increase surface interactions. It should be noted that this type of nature-inspired polymer also helps scientist increase the stability of the non-viral vector for further biomedical applications, even under harsh conditions. All of the discussed results were in good agreement with the TEM images as well (Fig. 3). TEM images demonstrated that in the presence of $\mathrm{CaP}$ and $\mathrm{Ca}$ NPs nanoparticles, the role of the chitosan substrate decreased and vanished due to the full coverage of these NPs.

\section{XRD results}

The synthesized nanoparticles and nanomaterials were characterized using XRD. In the XRD pattern for the synthesized CaNPs, the indicator planes of (100), (101), (102), (110), (111), (200), (201), (202), and (211), corresponding to the 2 Theta degrees of $28.5,34,47,50.5$ and 54.3 for the first five planes, conclude the successful synthesis of the CaNPs [83, 84]. In addition, the XRD pattern of $\mathrm{CaP}$ is in good agreement with JCPDS 9-0432, and demonstrated that the water peaks in the FTIR spectra did not cause structural deformation or changes in $\mathrm{CaP}[85,86]$. Furthermore, it is fair to assume that with the combination of these nanoparticles with chitosan, the peaks became slightly wider as the crystallinity decreased. As clearly shown in the XRD pattern of the synthesized nanomaterials, the indicator diffractions were slightly wider than the pure nanoparticles but the structure of the synthesized nanoparticles remained intact, indicating the successful incorporation of these synthesized nanoparticles into the chitosan structure (Fig. 4A).

\section{FTIR results}

The synthesized nanoparticles and nanomaterials were characterized using FTIR. In the Ca NP spectrum, a peak around $870 \mathrm{~cm}^{-1}$ indicated $\mathrm{Ca}-\mathrm{O}-\mathrm{Ca}$ bonding, while another peak at $710 \mathrm{~cm}^{-1}$ is an indicator of Ca-O bonding (Fig. 4B). In addition, a series of broad peaks at around 3500, 2950, 1790, and $1430 \mathrm{~cm}^{-1}$ belong to hydroxyl, carboxylic acid, amine, and amide functional groups on the surface of the green synthesized CaNPs or in the media of the green synthesis protocol, respectively. The CaNP FTIR spectrum is in good agreement with the previous reports as well [87-89].

In the CaP spectrum, two peaks at around $1040 \mathrm{~cm}^{-1}$ and $962 \mathrm{~cm}^{-1}$ indicated the presence of phosphate. A very
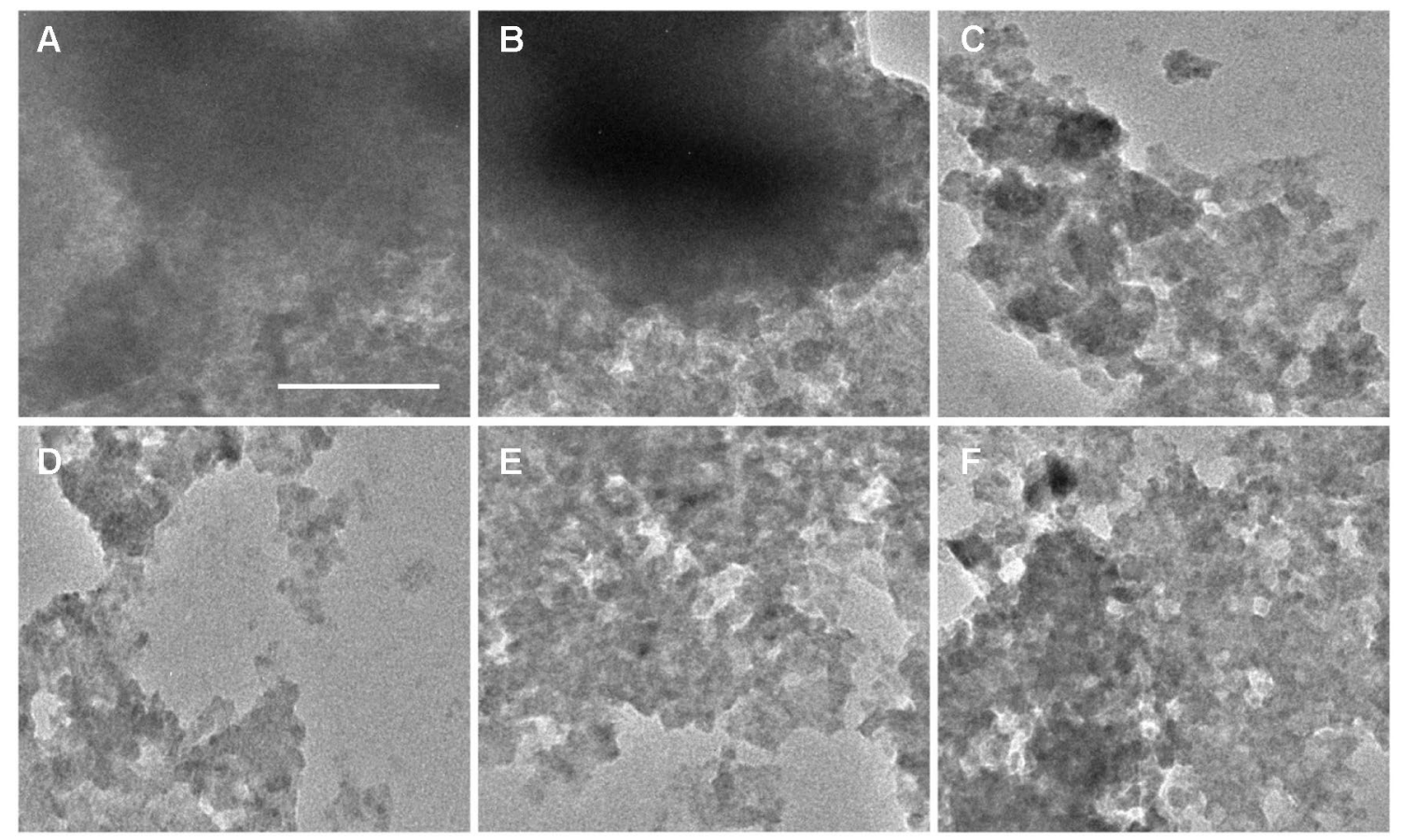

Fig. 3 TEM images of the synthesized nanomaterials; A chitosan, B CaP, C Ca NPs, D CaP Chitosan, E Ca NPs Chitosan, and F CaP/Ca NPs Chitosan. The scale bar is $100 \mathrm{~nm}$ 

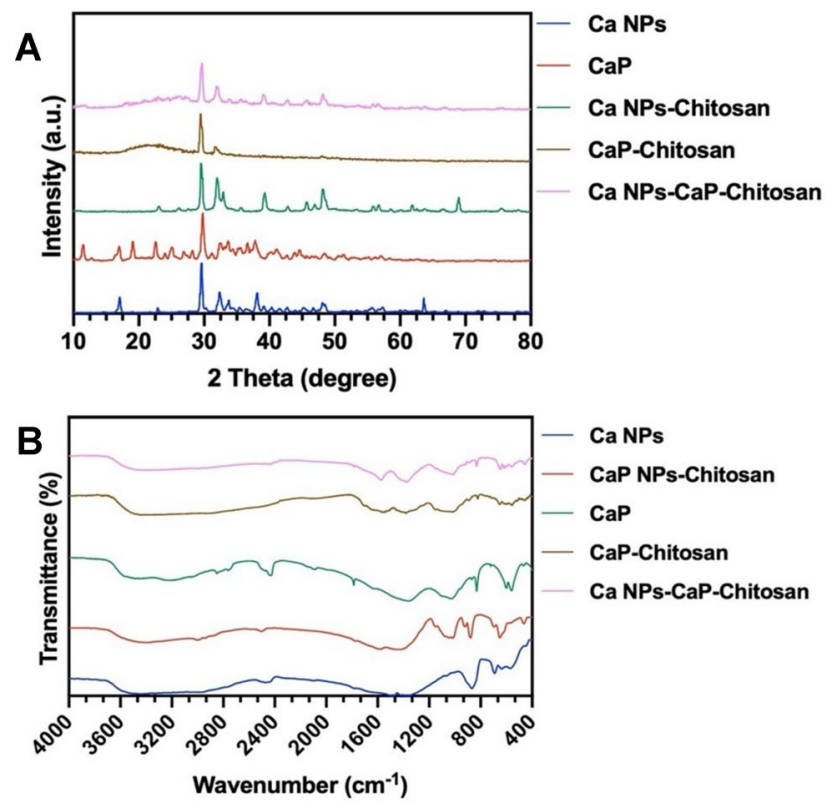

Fig. 4 Physicochemical properties of the synthesized nanoparticles and nanomaterials, A powder XRD (PXRD) pattern and B FTIR spectra

low band at around $950 \mathrm{~cm}^{-1}$ - that could overlap with the intense band of phosphate-was assigned to the vibration of the P-OH groups. In the range of $3100-3300 \mathrm{~cm}^{-1}$, a broad band was assigned to the overlapping hydrogen vibrations of the structural hydroxyl stretching vibrations and physically adsorbed water. Also, a low-intensity band at around $1630 \mathrm{~cm}^{-1}$ was assigned to the bending vibrations of the adsorbed water. A low-intensity band at around $560 \mathrm{~cm}^{-1}$ revealed the presence of trace phosphate ions as well. The FTIR spectrum of $\mathrm{CaP}$ was in good agreement with the literature [90, 91].

In the FTIR spectra of CaNPs-Chitosan, CaP-Chitosan, and CaNPs-CaP-Chitosan, all of the indicator bands for $\mathrm{CaNPs}$ and $\mathrm{CaP}$ as mentioned above were observed, and a broad band at about $3400 \mathrm{~cm}^{-1}$ was assigned to the axial $\mathrm{O}-\mathrm{H}$ and $\mathrm{N}-\mathrm{H}$ stretching of chitosan which overlapped the $\mathrm{C}-\mathrm{H}$ stretching band around $2800 \mathrm{~cm}^{-1}$. The band around $1650 \mathrm{~cm}^{-1}$ indicated the axial $\mathrm{C}=\mathrm{O}$ stretching of the acetamido groups of chitosan, while the semi-broad band around $1580 \mathrm{~cm}^{-1}$ was attributed to the $\mathrm{N}-\mathrm{H}$ bonds (angular deformation) of the amino groups of chitosan. In addition, broad bands around $1420-1470 \mathrm{~cm}^{-1}$ could be assigned to the $\mathrm{N}-\mathrm{H}$ angular deformation coupling as well as the $\mathrm{C}-\mathrm{N}$ axial stretching, which certainly overlapped and was represented as a single broad band. Finally, the fingerprint of the presence of chitosan in the structures was confirmed by bands around $1100 \mathrm{~cm}^{-1}$ and $900 \mathrm{~cm}^{-1}$, which were attributed to the vibration of glycosidic bonds- the $\mathrm{C}-\mathrm{O}$ and $\mathrm{C}-\mathrm{O}-\mathrm{C}$ stretching bonds, respectively. The FTIR spectra of all of the synthesized nanomaterials are in good agreement with the previous reports $[92,93]$.

\section{Zeta potential of the nanocomplexes}

The physical and chemical properties-including surface charge, size, and hydrophobicity - should be considered to develop an ideal nanocarrier to effectively deliver a wide range of therapeutics $[84,94,95]$. The zeta potential of the CaNPs/pCRISPR was -11 and -37 for the M/pCRISPR (M/C) of 10 and 100, respectively (Fig. 5A). Additionally, the zeta potential of the $\mathrm{CaP} / \mathrm{pCRISPR}$ nanocomplexes was -6 and -17 for $\mathrm{WR}(\mathrm{M} / \mathrm{C})$ of 10 and 100 , respectively. In this case, the zeta potential of the CaNPs-Chitosan/pCRISPR and CaP-Chitosan/pCRISPR nanocomplexes was -4 , and $-2 \mathrm{mV}$ for the $\mathrm{WR}(\mathrm{M} / \mathrm{C})=10$, and these numbers shifted dramatically to +12 and $+11 \mathrm{mV}$ for the $W R(M / C)=100$. The zeta potential of the modified chitosan with both of CaNPs and CaP and pCRISPR were $+2,+5,+11,+21$ and +27 for the $\mathrm{WR}(\mathrm{M} / \mathrm{C})=10,20$, 30,50 and 100 , respectively.

\section{Formation of the nanoplatform}

The results of gel electrophoresis (Fig. 5B) showed different interaction strengths between the nanomaterial and pCRISPR with enhancing ratios are demonstrated through the intensity of the pCRISPR migration bonds. Based on the previous work [96], CaP has a weak ability to condense pDNA. Yet, in this study, the synthesized CaP showed better results than what would come from just the synthesis procedure. The same results were found for CaNPs, but interestingly, as the zeta potential of these nanoparticles was negative, gel electrophoresis showed a better outcome resulting from the green synthesis medium of these nanoparticles, which is likely due to the presence of calcium in ionic form and the successful electrostatic interaction with DNA.

Furthermore, the influence of chitosan on the performance of $\mathrm{CaP}$ and CaNPs in gene delivery was investigated, as shown in Fig. 5A. By increasing the zeta potential, the slope increased and the genetic material bonding improved due to the higher positive zeta potential.

\section{Cell viability assays}

In this part of the study, the cellular toxicity of the synthesized nanomaterials on the HEK-293 cell lines were investigated (Fig. 5C). It was found that all of the synthesized nanomaterials showed considerably high relative cell viability on the HEK-293 cells (at a viability of more than $85 \%$ ) at different concentrations of the synthesis procedure. PEI and related conjugates (with an IC50 value of more than $25 \mu \mathrm{g} / \mathrm{mL}$ ), the presently synthesized nanomaterials and 

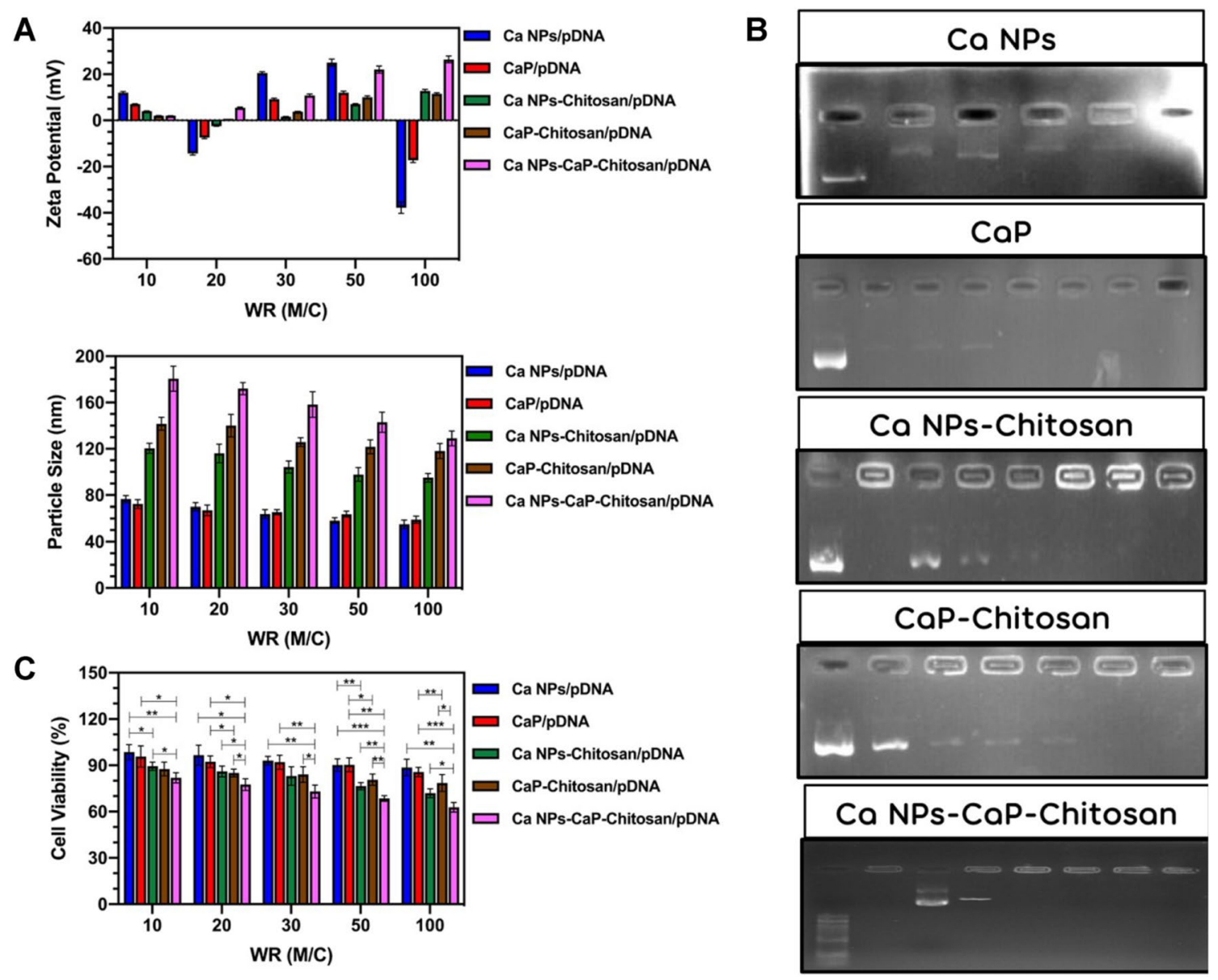

Fig. 5 The results of $\mathbf{A}$ zeta potential and particle size, $\mathbf{B}$ gel electrophoresis. The first col. is the control, and by shifting to the left, the weight ratio of the nanocarrier to the genetic materials increased by doubling the amount. The first amount (second col.) is WR

nanoparticles-especially CaNPs-Chitosan (with an IC50 value of about $21 \mu \mathrm{g} / \mathrm{mL}$ ), CaP-Chitosan (with an IC50 value of about $16 \mu \mathrm{g} / \mathrm{mL}$ ) and CaNPs-CaP-Chitosan (with an IC50 value below $15 \mu \mathrm{g} / \mathrm{mL}$ ) — have very low toxicity. This result makes such nanomaterials promising candidates as the next-generation gold standard non-viral gene delivery vector.

\section{In vitro gene expression efficiency}

In order to evaluate gene expression efficiency, pCRISPR expressing GFP studies were conducted using the HEK-293 cell line. Comprehensive fluorescence microscopy images were obtained to evaluate EGFP expression on the mentioned cells at different concentrations of the nanomaterials and pCRISPR (Figs. 6A-J and 7) along with optical microscopy (Fig. 6L-O). The results indicate that by enhancing the weight ratio, the gene transfection efficiency significantly increased (Fig. 6K). Additionally, the best result from the of 1), and $\mathbf{C}$ relative cell viability of the synthesized nanoplexes. Gel electrophoresis, zeta potential, size, and relative cell viability are presented for $72 \mathrm{~h}$ as the mean $( \pm \mathrm{SD})$ from three experiments. $(* P$-value $<0.05, * * P$-value $<0.01$ and $* * * P$-value $<0.001)$

gene expression of EGFP was about $25 \%$ for the HEK-293 cells for CaP-Chitosan. Following papers in the literature, several factors are associated with transfection efficiency, including the size of the genetic material as well as the polymeric length [97-99] but to the best of our knowledge, so far, no reports have claimed significant transfection efficiency with low cost using an environmentally friendly non-viral vector without costly and difficult optimization. Furthermore, after full consideration of the in vitro studies, CaNPs Chitosan, CaP Chitosan, and CaNPs CaP Chitosan were regenerated and studied under microscopic conditions (Supporting Information; Figs. S1, S2, and S3) showing no significant morphological changes after gene transfection.

\section{Insight into the mechanism}

Investigating the effect of different types of nanoparticles and nanomaterials as non-viral gene delivery vectors on different cell lines is of great importance. The ability of 
Fig. 6 The results from 2D fluorescence microscopy of CaNPs with the WR of $50(\mathbf{A})$ and 100 (B); $\mathrm{CaP}$ with the WR of 50 (C) and 100 (D); CaNPs Chitosan with the WR of $50(\mathbf{E})$ and 100 (F); CaP Chitosan with the WR of $50(\mathbf{G})$ and $100(\mathbf{H})$; CaNPs/ $\mathrm{CaP}$ Chitosan with the WR of 50 (I) and $100(\mathbf{J})$ (The scale bar is $50 \mu \mathrm{m}$ ); $\mathbf{K}$ GFP positive cells for the synthesis materials at different WRs on the HEK293 cell line; and also optical microscopy of $\mathrm{CaP}$ Chitosan with the WR of $20(\mathbf{L})$ and 50 (N); and CaNPs/CaP Chitosan with the WR of $20(\mathbf{M})$ and 50 (O) (magnification; $\times 80$ ). 2D fluorescence microscopy and EGFP are presented as the mean $( \pm \mathrm{SD})$ from three experiments. ( $* P$-value $<0.05$, $* * * P$-value $<0.01$ and $* * * * P$-value $<0.0001)$
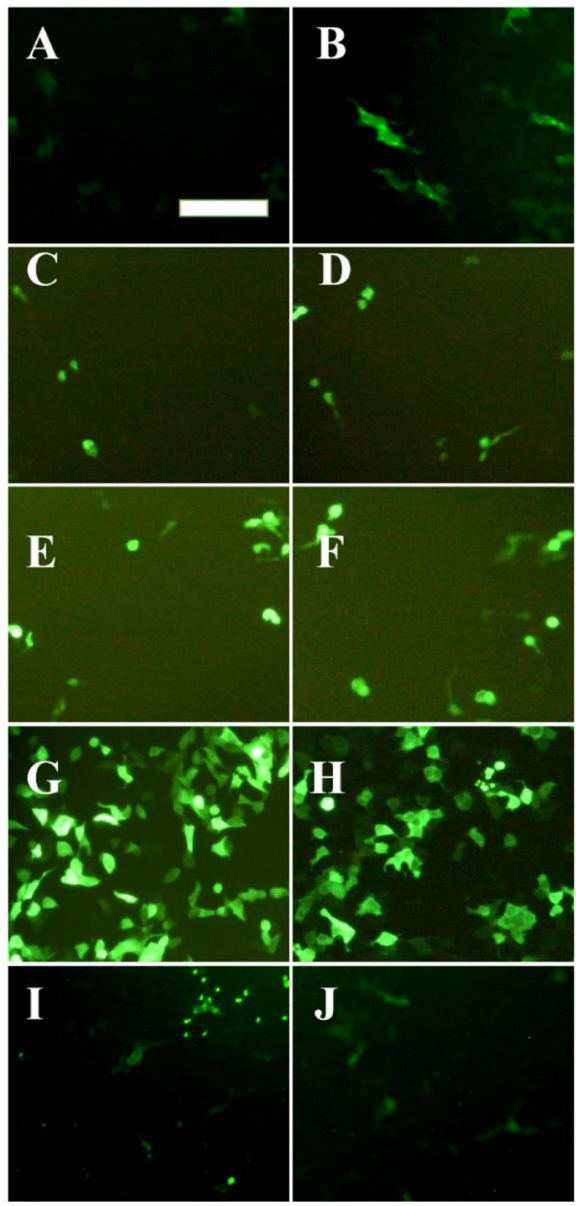

K
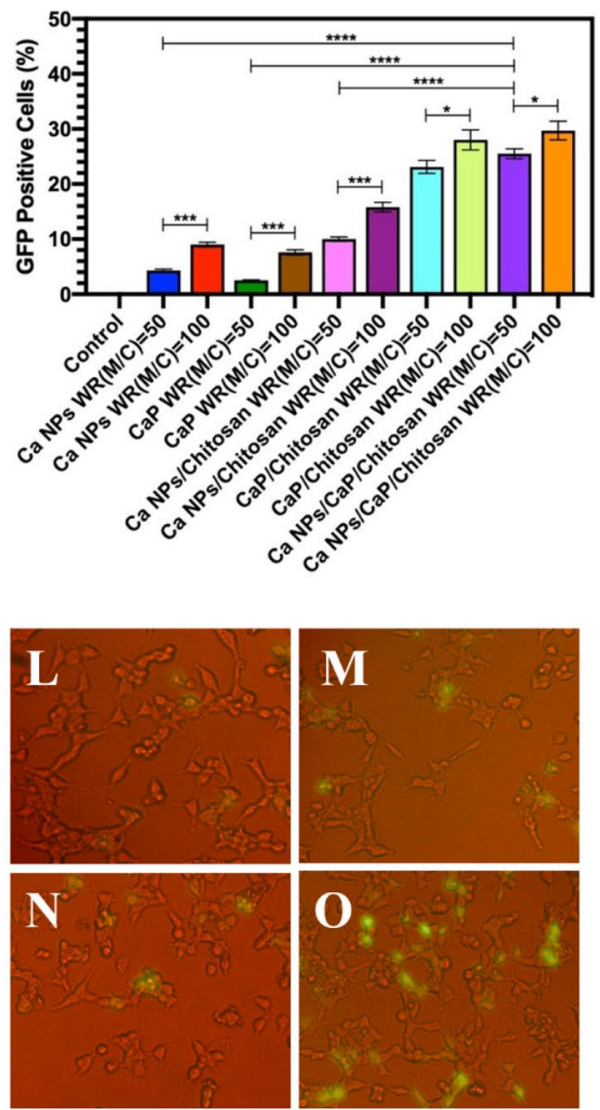

Fig. 7 2D fluorescence microscopy results of the CaNPs Chitosan (A-D) and CaP Chitosan $(\mathbf{E}-\mathbf{H})$ on the HEK-293 cell line. The scale bar is $10 \mu \mathrm{m}$
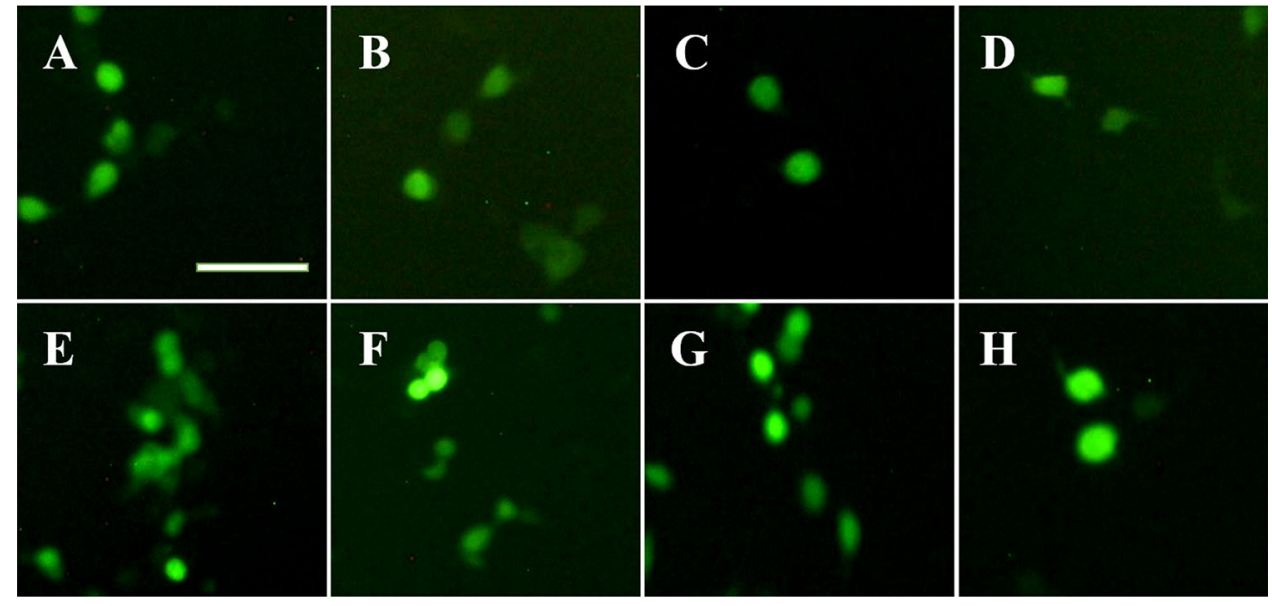

endosomal escape is one of the most important parts for the biomedical applications, especially in case of gene therapy and delivery. In this regard, the underlying mechanism for this effect has been called a proton sponge. The proton sponge effect is the ability of basic molecules to be protonated resulting in endosome bursting. In this study, one of the main reasons for the great efficiency of these synthesized nanomaterials is their buffering capacity. To evaluate their buffering capacity, adsorption ability studies of the nanostructures in the presence of different transition metals have been performed. The sorption isotherms of $\mathrm{Cd}^{2+}, \mathrm{Cu}^{2+}$, and $\mathrm{Pb}^{2+}$ of the synthesized nanoparticles and nanomaterials were demonstrated the $\mathrm{H}$ and $\mathrm{L}$ types of Giles classifications [100, 101] (Fig. 8). 

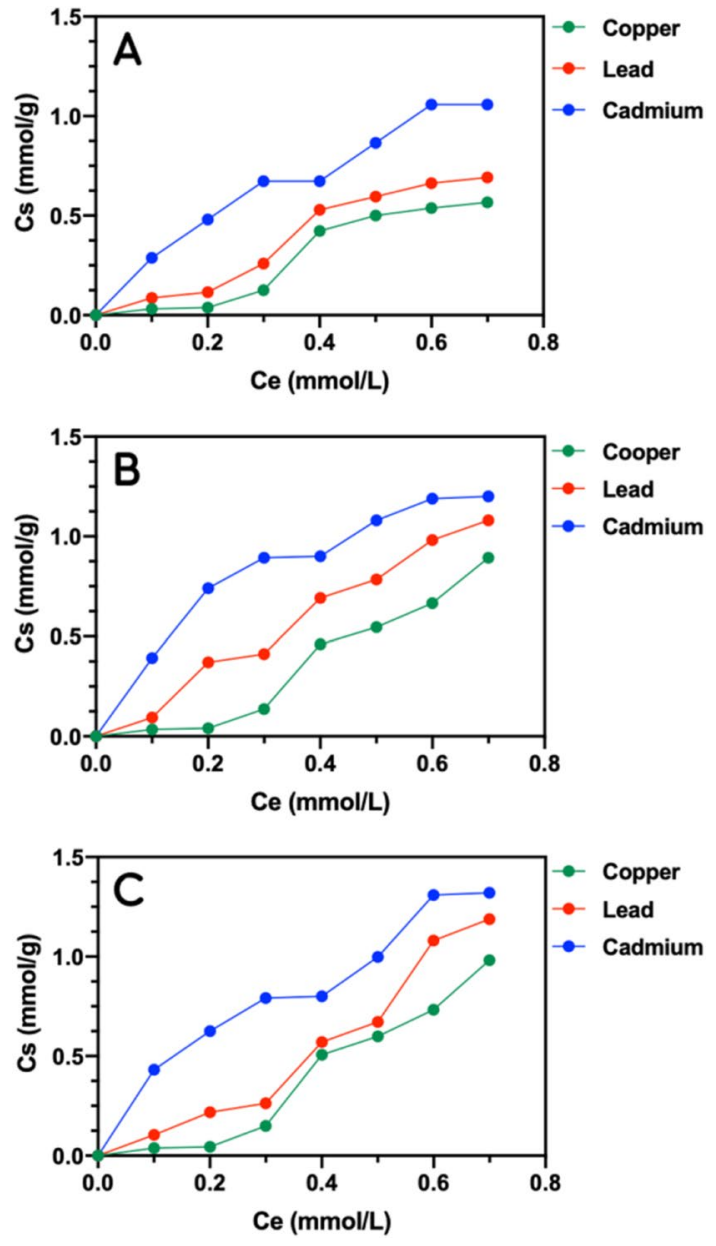

Fig. 8 The sorption isotherms of $\mathrm{Cu}^{2+}, \mathrm{Pb}^{2+}$ and $\mathrm{Cd}^{2+}$ on the synthesized CaNPs/Chitosan (A), CaP/Chitosan (B) and CaNPs/CaP/Chitosan $(\mathbf{C})$

\section{Discussion}

Previous works showed that $[102,103]$ the good nanocarrier for gene delivery procedure should have higher positive zeta potential. In addition, shifting to a negative phase was expected by adding pCRISPR to the CaNPs and $\mathrm{CaP}$ nanocomplexes $[104,105]$. Furthermore, some papers emphasized successful gene transfection with negative or even neutral zeta potential [106], but based on our knowledge, to get materials into the clinical or industrial phase, results have to be extraordinary; in this manner, a positive zeta potential is critical. This phenomenon, shifting the zeta potential by changing the concentration and weight ratio, could be correlated to the presence of different types of functional groups on the surface, leading to significant aggregation and agglomeration. These aggregations and interactions change the microenvironment around the nanomaterials, which in turn will change zeta potential and particle size.
Physical, chemical and biological stability of a nanoplatform for every biomedical application is of great importance [107-109]. Amine functional groups of chitosan can increase the efficiency of interactions with the pCRISPR phosphate backbone, and interestingly, this mechanism is considered in the wide range of $\mathrm{pH}$ and physicochemical conditions. From another perspective, it has been revealed that $\mathrm{CaP}$ has an ability for DNA condensation; therefore, $\mathrm{CaP}$ possesses a synergic effect on pCRISPR condensation along with chitosan. Until now, there have been no reports investigating this synergic effect, including the role of calcium itself. In this study, the ability of CaNPs to condense genetic material was investigated. However, the hydroxyl groups on the surface of the nanoparticles make their zeta potential shift more towards the negative region, and the potential electrostatic interaction between those nanoparticles and pCRISPR are quite weak. But, the ability of the Ca NP synergic effect on CaP and chitosan is still unknown, and this research was conducted to understand such phenomena.

The effect of the presence of both CaP and CaNPs in the chitosan structure revealed very interesting results in terms of both relative cell viability and gel electrophoresis analysis. In this regard, the nanoparticles have a synergic effect on each other in the chitosan structure, and they likely prevent probable aggregation through electrostatic forces and via the functional groups on their surface. Furthermore, another theory can be put forward herein that the calcium nanoparticle can cause charge separation on the surface of the chitosan in the presence of calcium phosphate; thus, it can reduce the number of nanoparticles-or rather, the nanomaterials - that accumulate. These accumulated nanomaterials then reduce the size of the final nanomaterial that condense DNA, which lead to a reduction in the size of the final nanomaterial improving transfection efficiency, both of which are revealed in this study.

Generally, by increasing the ratio to above 2, the migration of pCRISPR was confined, which is proof of genetic material condensation by the synthesized nanomaterials and nanoparticles in this study at low weight ratios. Therefore, the pyrolysis time was exactly selected to be an optimal balance between the surface modification of chitosan and $\mathrm{N}$-doping, leading to significant gene condensing.

Based on the literature [110-112], by increasing the time of radiation, cytotoxicity decreases gradually due to the deterioration of amino groups, which was also exhibited in this research. However, this trend was not observed for the synthesized $\mathrm{CaP}$ and CaNPs, due to the absence of nitrogen-based compounds. Additionally, by increasing the PEI concentration on the surface, the relative cell viability reduced with much higher slope compared to the synthesized CaNPs-Chitosan, CaP-Chitosan, and CaNPs-CaP-Chitosan [76, 113]. This can be correlated to the chemistry of chitosan and the synergic effect of those 
nanoparticles in condensing pCRISPR and preventing aggregation. In comparison with PEI, this makes amino groups less accessible, and, as a result, an increase in the concentration of the synthesized nanomaterials reduces cell viability rate, resulting in a less steep slope. All in all, these results are consistent with the literature [114, 115]. Our findings are considered the first to report on replacing PEI with a semi-green and cost-effective, yet more effective, nanomaterial in pCRISPR delivery $[116,117]$.

In this work, the used metal ions can affect the environmental $\mathrm{pH}$, and the synthesized nanomaterial buffering capacity inhibits the unwanted effect of other parameters on changing $\mathrm{pH}$ values. The $\mathrm{pH}$ of the nanocomplexes on the sorption process of the metal ions was recorded at 7.4 to 8.6 , which could be considered as proof that these metals were in metal hydroxide form $[118,119]$.

This work aimed to investigate the role of carbonbased nanomaterials and different forms of calcium in green media as smart gene delivery systems. In this case, CaNPs and $\mathrm{CaP}$ were selected as different forms of calcium, and chitosan was selected as the carbon-based carrier. Different nanomaterials were prepared based on the above-mentioned calcium forms and chitosan, and were fully characterized in terms of their chemical, physical and biological properties. The chemical characterization proved the successful synthesis of these nanoparticles and nanomaterials, and fully biomedical characterization represents a significant ability of the genetic material to make a bind to the nanoplatform, with having considerably high relative cell viability.

Supplementary Information The online version contains supplementary material available at https://doi.org/10.1007/s40097-021-00446-1.

Acknowledgements We acknowledge the Sharif University of Technology Research Council for supporting this research.

\section{Declarations}

Conflict of interests The authors declare that they have no conflicts of interest with the present study.

\section{References}

1. Naldini, L.: Gene therapy returns to centre stage. Nature 526(7573), 351 (2015)

2. Ahmadi, S., Rabiee, N., Bagherzadeh, M., Elmi, F., Fatahi, Y., Farjadian, F., Baheiraei, N., Nasseri, B., Rabiee, M., Dastjerd, N.T.: Stimulus-responsive sequential release systems for drug and gene delivery. Nano Today 34, 100914 (2020)

3. Rabiee, N., Bagherzadeh, M., Ghadiri, A.M., Salehi, G., Fatahi, Y., Dinarvand, R.: ZnAl nano layered double hydroxides for dual functional CRISPR/Cas9 delivery and enhanced green fluorescence protein biosensor. Sci. Rep. 10(1), 1-15 (2020)
4. Bagherzadeh, M., Rabiee, N., Fattahi, Y., Dinarvand, R.: Znrich $(\mathrm{GaN}) 1-\mathrm{x}(\mathrm{ZnO}) \mathrm{x}$ : a biomedical friend? New J. Chem. 45, 4077-4089 (2021)

5. Karimi, M., Ghasemi, A., Zangabad, P.S., Rahighi, R., Basri, S.M.M., Mirshekari, H., Amiri, M., Pishabad, Z.S., Aslani, A., Bozorgomid, M.: Smart micro/nanoparticles in stimulusresponsive drug/gene delivery systems. Chem. Soc. Rev. 45(5), 1457-1501 (2016)

6. Lin, G., Zhang, H., Huang, L.: Smart polymeric nanoparticles for cancer gene delivery. Mol. Pharm. 12(2), 314-321 (2015)

7. Cheng, Y., Sun, C., Liu, R., Yang, J., Dai, J., Zhai, T., Lou, X., Xia, F.: A multifunctional peptide-conjugated AIEgen for efficient and sequential targeted gene delivery into the nucleus. Angew. Chem. 131(15), 5103-5107 (2019)

8. Hajebi, S., Rabiee, N., Bagherzadeh, M., Ahmadi, S., Rabiee, M., Roghani-Mamaqani, H., Tahriri, M., Tayebi, L., Hamblin, M.R.: Stimulus-responsive polymeric nanogels as smart drug delivery systems. Acta Biomater. 92, 1-18 (2019)

9. Amani, H., Mostafavi, E., Arzaghi, H., Davaran, S., Akbarzadeh, A., Akhavan, O., Pazoki-Toroudi, H., Webster, T.J.: Threedimensional graphene foams: synthesis, properties, biocompatibility, biodegradability, and applications in tissue engineering. ACS Biomater. Sci. Eng. 5(1), 193-214 (2018)

10. Liu, C., Zhang, L., Liu, H., Cheng, K.: Delivery strategies of the CRISPR-Cas9 gene-editing system for therapeutic applications. J. Control. Release 266, 17-26 (2017)

11. Mout, R., Ray, M., Yesilbag Tonga, G., Lee, Y.-W., Tay, T., Sasaki, K., Rotello, V.M.: Direct cytosolic delivery of CRISPR/ Cas9-ribonucleoprotein for efficient gene editing. ACS Nano 11(3), 2452-2458 (2017)

12. Su, T., Liu, F., Gu, P., Jin, H., Chang, Y., Wang, Q., Liang, Q., Qi, Q.: A CRISPR-Cas9 assisted non-homologous end-joining strategy for one-step engineering of bacterial genome. Sci. Rep. 6(1), 1-11 (2016)

13. Yamato, T., Handa, A., Arazoe, T., Kuroki, M., Nozaka, A., Kamakura, T., Ohsato, S., Arie, T., Kuwata, S.: Single crossovermediated targeted nucleotide substitution and knock-in strategies with CRISPR/Cas9 system in the rice blast fungus. Sci. Rep. 9(1), 1-8 (2019)

14. Rabiee, N., Bagherzadeh, M., Ghadiri, A.M., Kiani, M., Fatahi, Y., Tavakolizadeh, M., Pourjavadi, A., Jouyandeh, M., Saeb, M.R., Mozafari, M.: Multifunctional 3D hierarchical bioactive green carbon-based nanocomposites. ACS Sustain. Chem. Eng. 92, 8706-8720 (2021)

15. Yin, H., Song, C.-Q., Dorkin, J.R., Zhu, L.J., Li, Y., Wu, Q., Park, A., Yang, J., Suresh, S., Bizhanova, A.: Therapeutic genome editing by combined viral and non-viral delivery of CRISPR system components in vivo. Nat. Biotechnol. 34(3), 328 (2016)

16. Yin, H., Kauffman, K.J., Anderson, D.G.: Delivery technologies for genome editing. Nat. Rev. Drug Discov. 16(6), 387 (2017)

17. Cokca, C., Zartner, L., Tabujew, I., Fischer, D., Peneva, K.: Incorporation of indole significantly improves the transfection efficiency of guanidinium-containing poly (Methacrylamide). Macromol. Rapid Commun. 41(6), 1900668 (2020)

18. Alhakamy, N.A., Alaofi, A.L., Ahmed, O.A., Fahmy, U.A.M.D.S., Abdulaal, W.H., Alfaleh, M.A., Chakraborty, A., Berkland, C.J., Dhar, P.: Development of lipid membrane based assays to accurately predict the transfection efficiency of cellpenetrating peptide-based gene nanoparticles. Int. J. Pharm. 580, 119221 (2020)

19. Mout, R., Ray, M., Lee, Y.-W., Scaletti, F., Rotello, V.M.: In vivo delivery of CRISPR/Cas9 for therapeutic gene editing: progress and challenges. Bioconjug. Chem. 28(4), 880-884 (2017)

20. Crudele, J.M., Chamberlain, J.S.: Cas9 immunity creates challenges for CRISPR gene editing therapies. Nat. Commun. 9(1), 3497 (2018) 
21. Ahmadi, S., Rabiee, N., Bagherzadeh, M., Karimi, M.: Microfluidic devices for gene delivery systems. In: Karimi, M., Hamblin, M.R. (eds.) Biomedical Applications of Microfluidic Devices, pp. 187-208. Elsevier (2021)

22. Komaroff, A.L.: Gene editing using CRISPR: why the excitement? JAMA 318(8), 699-700 (2017)

23. Tong, S., Moyo, B., Lee, C.M., Leong, K., Bao, G.: Engineered materials for in vivo delivery of genome-editing machinery. Nat. Rev. Mater. 11, 1-12 (2019)

24. Saeb, M.R., Rabiee, N., Mozafari, M., Mostafavi, E.: Metalorganic frameworks-based nanomaterials for drug delivery. Materials 14(13), 3652 (2021)

25. Yin, H., Xue, W., Anderson, D.G.: CRISPR-Cas: a tool for cancer research and therapeutics. Nat. Rev. Clin. Oncol. 16(5), 281-295 (2019)

26. Buck, J., Grossen, P., Cullis, P.R., Huwyler, J.R., Witzigmann, D.: Lipid-based DNA therapeutics: hallmarks of non-viral gene delivery. ACS Nano 13(4), 3754-3782 (2019)

27. Chin, J.S., Chooi, W.H., Wang, H., Ong, W., Leong, K.W., Chew, S.Y.: Scaffold-mediated non-viral delivery platform for CRISPR/ Cas9-based genome editing. Acta Biomater. 90, 60-70 (2019)

28. Liu, M.-X., Ma, L.-L., Liu, X.-Y., Liu, J.-Y., Lu, Z.-L., Liu, R., He, L.: Combination of [12] aneN3 and Triphenylamine-Benzylideneimidazolone (TPA-BI) as Non-viral Gene Vectors with Two-photon and AIE Properties. ACS Appl. Mater. Interfaces. 4, 42975-42987 (2019)

29. Medina-Cruz, D., Mostafavi, E., Vernet-Crua, A., Cheng, J., Shah, V., Cholula-Diaz, J.L., Guisbiers, G., Tao, J., GarcíaMartín, J.M., Webster, T.J.: Green nanotechnology-based drug delivery systems for osteogenic disorders. Expert Opin Drug Deliv. 17(3), 341-356 (2020)

30. Soltantabar, P., Calubaquib, E.L., Mostafavi, E., Biewer, M.C., Stefan, M.C.: Enhancement of loading efficiency by coloading of doxorubicin and quercetin in thermoresponsive polymeric micelles. Biomacromol 21(4), 1427-1436 (2020)

31. Gao, Y., Huang, J.-Y., O'Keeffe Ahern, J., Cutlar, L., Zhou, D., Lin, F.-H., Wang, W.: Highly branched poly ( $\beta$-amino esters) for non-viral gene delivery: high transfection efficiency and low toxicity achieved by increasing molecular weight. Biomacromol 17(11), 3640-3647 (2016)

32. Radmanesh, F., Kiani, J., Bayandori, M., Fatahi, Y., Aref, A., Karimi, M.: Photoluminescent Functionalized Carbon Dots for CRISPR delivery: synthesis, optimization and cellular investigation. Nanotechnology 30, 135101 (2019)

33. Timin, A.S., Muslimov, A.R., Lepik, K.V., Epifanovskaya, O.S., Shakirova, A.I., Mock, U., Riecken, K., Okilova, M.V., Sergeev, V.S., Afanasyev, B.V.: Efficient gene editing via non-viral delivery of CRISPR-Cas9 system using polymeric and hybrid microcarriers. Nanomed. Nanotechnol. Biol. Med. 14(1), 97-108 (2018)

34. Ryu, N., Kim, M.-A., Park, D., Lee, B., Kim, Y.-R., Kim, K.-H., Baek, J.-I., Kim, W.J., Lee, K.-Y., Kim, U.-K.: Effective PEImediated delivery of CRISPR-Cas9 complex for targeted gene therapy. Nanomed. Nanotechnol. Biol. Med. 14(7), 2095-2102 (2018)

35. Sun, W., Ji, W., Hall, J.M., Hu, Q., Wang, C., Beisel, C.L., Gu, Z.: Self-assembled DNA nanoclews for the efficient delivery of CRISPR-Cas9 for genome editing. Angew. Chem. Int. Ed. 54(41), 12029-12033 (2015)

36. Liu, Q., Zhao, K., Wang, C., Zhang, Z., Zheng, C., Zhao, Y., Zheng, Y., Liu, C., An, Y., Shi, L.: Multistage delivery nanoparticle facilitates efficient CRISPR/dCas9 activation and tumor growth suppression in vivo. Adv. Sci. 6(1), 1801423 (2019)

37. Wang, Y., Cao, P., Li, S., Zhang, X., Hu, J., Yang, M., Yao, S., Gao, F., Xia, A., Shen, J.: Layer-by-layer assembled PEI-based vector with the upconversion luminescence marker for gene delivery. Biochem Biophys Res Commun. 503(4), 2504-2509 (2018)

38. Eoh, J., Gu, L.: Biomaterials as vectors for the delivery of CRISPR-Cas9. Biomater. Sci. 7(4), 1240-1261 (2019)

39. Kretzmann, J.A., Ho, D., Evans, C.W., Plani-Lam, J.H., Garcia-Bloj, B., Mohamed, A.E., O’Mara, M.L., Ford, E., Tan, D.E., Lister, R.: Synthetically controlling dendrimer flexibility improves delivery of large plasmid DNA. Chem. Sci. 8(4), 2923-2930 (2017)

40. Tan, Z., Jiang, Y., Zhang, W., Karls, L., Lodge, T.P., Reineke, T.M.: Polycation architecture and assembly direct successful gene delivery: micelleplexes outperform polyplexes via optimal DNA packaging. J. Am. Chem. Soc. 141(40), 1580415817 (2019)

41. Luong, D., Kesharwani, P., Deshmukh, R., Amin, M.C.I.M., Gupta, U., Greish, K., Iyer, A.K.: PEGylated PAMAM dendrimers: Enhancing efficacy and mitigating toxicity for effective anticancer drug and gene delivery. Acta Biomater. 43, 14-29 (2016)

42. Lee, S., Son, S., Song, S., Ha, T., Choi, J.: Polyamidoamine (PAMAM) dendrimers modified with cathepsin-B cleavable oligopeptides for enhanced gene delivery. Polymers 9(6), 224 (2017)

43. Mandal, H., Katiyar, S.S., Swami, R., Kushwah, V., Katare, P.B., Meka, A.K., Banerjee, S.K., Popat, A., Jain, S.: $\varepsilon$-Poly-1-lysine/ plasmid DNA nanoplexes for efficient gene delivery in vivo. Int. J. Pharm. 542(1-2), 142-152 (2018)

44. Walsh, D.P., Murphy, R.D., Panarella, A., Raftery, R.M., Cavanagh, B., Simpson, J.C., O’Brien, F.J., Heise, A., Cryan, S.-A.: Bioinspired star-shaped poly (L-lysine) polypeptides: efficient polymeric nanocarriers for the delivery of DNA to mesenchymal stem cells. Mol. Pharm. 15(5), 1878-1891 (2018)

45. Taranejoo, S., Chandrasekaran, R., Cheng, W., Hourigan, K.: Bioreducible PEI-functionalized glycol chitosan: a novel gene vector with reduced cytotoxicity and improved transfection efficiency. Carbohydr. Polym. 153, 160-168 (2016)

46. Raja, M.A.G., Katas, H., Wen, T.J.: Stability, intracellular delivery, and release of siRNA from chitosan nanoparticles using different cross-linkers. PLoS ONE 10(6), e0128963 (2015)

47. Wang, M., Guo, Y., Xue, Y., Niu, W., Chen, M., Ma, P.X., Lei, B.: Engineering multifunctional bioactive citric acid-based nanovectors for intrinsical targeted tumor imaging and specific siRNA gene delivery in vitro/in vivo. Biomaterials 199, 10-21 (2019)

48. Wilson, D.R., Rui, Y., Siddiq, K., Routkevitch, D., Green, J.J.: Differentially branched ester amine quadpolymers with amphiphilic and $\mathrm{pH}$-sensitive properties for efficient plasmid DNA delivery. Mol. Pharm. 16(2), 655-668 (2019)

49. Abdelhamid, H.N., Dowaidar, M., Hällbrink, M., Langel, Ü.: Gene delivery using cell penetrating peptides-zeolitic imidazolate frameworks. Microporous. Mesoporous. Mater. 300, $110173(2020)$

50. Liu, S., Gao, Y., Zhou, D., Zeng, M., Alshehri, F., Newland, B., Lyu, J., O'Keeffe-Ahern, J., Greiser, U., Guo, T.: Highly branched poly ( $\beta$-amino ester) delivery of minicircle DNA for transfection of neurodegenerative disease related cells. Nat. Commun. 10(1), 1-14 (2019)

51. Zeng, M., Alshehri, F., Zhou, D., Lara-Sáez, I., Wang, X., Li, X., Xu, Q., Zhang, J., Wang, W.: Efficient and robust highly branched poly ( $\beta$-amino ester)/Minicircle COL7A1 polymeric nanoparticles for gene delivery to recessive dystrophic epidermolysis bullosa keratinocytes. ACS Appl. Mater. Interfaces. 11(34), 30661-30672 (2019)

52. Zhou, D., Cutlar, L., Gao, Y., Wang, W., O'Keeffe-Ahern, J., McMahon, S., Duarte, B., Larcher, F., Rodriguez, B.J., Greiser, U.: The transition from linear to highly branched poly ( $\beta$-amino 
ester) s: Branching matters for gene delivery. Sci. Adv. 2(6), e1600102 (2016)

53. Dowaidar, M., Nasser Abdelhamid, H., Hällbrink, M., Langel, Ü., Zou, X.: Chitosan enhances gene delivery of oligonucleotide complexes with magnetic nanoparticles-cell-penetrating peptide. J. Biomater. Appl. 33(3), 392-401 (2018)

54. Dowaidar, M., Abdelhamid, H.N., Hällbrink, M., Zou, X., Langel, Ü.: Graphene oxide nanosheets in complex with cell penetrating peptides for oligonucleotides delivery. Biochim. Biophys. Acta Gen. Subj. 1861(9), 2334-2341 (2017)

55. Thibault, M., Lavertu, M., Astolfi, M., Buschmann, M.D.: Structure dependence of lysosomal transit of chitosan-based polyplexes for gene delivery. Mol Biotechnol. 58(10), 648-656 (2016)

56. Lin, J.-T., Liu, Z.-K., Zhu, Q.-L., Rong, X.-H., Liang, C.-L., Wang, J., Ma, D., Sun, J., Wang, G.-H.: Redox-responsive nanocarriers for drug and gene co-delivery based on chitosan derivatives modified mesoporous silica nanoparticles. Colloids Surf B. Biointerfaces 155, 41-50 (2017)

57. Kwak, S.-Y., Lew, T.T.S., Sweeney, C.J., Koman, V.B., Wong, M.H., Bohmert-Tatarev, K., Snell, K.D., Seo, J.S., Chua, N.-H., Strano, M.S.: Chloroplast-selective gene delivery and expression in planta using chitosan-complexed single-walled carbon nanotube carriers. Nat. Nanotechnol. 14(5), 447 (2019)

58. Zhang, H., Bahamondez-Canas, T.F., Zhang, Y., Leal, J., Smyth, H.D.: PEGylated chitosan for nonviral aerosol and mucosal delivery of the CRISPR/Cas9 system in vitro. Mol. Pharm. 15(11), 4814-4826 (2018)

59. Santos-Carballal, B., Fernández Fernández, E., Goycoolea, F.M.: Chitosan in non-viral gene delivery: Role of structure, characterization methods, and insights in cancer and rare diseases therapies. Polymers 10(4), 444 (2018)

60. Mobarakeh, V.I., Modarressi, M.H., Rahimi, P., Bolhassani, A., Arefian, E., Atyabi, F., Vahabpour, R.: Optimization of chitosan nanoparticles as an anti-HIV siRNA delivery vehicle. Int. J. Biol. Macromol. 129, 305-315 (2019)

61. Miller, J.B., Zhang, S., Kos, P., Xiong, H., Zhou, K., Perelman, S.S., Zhu, H., Siegwart, D.J.: Non-viral CRISPR/Cas gene editing in vitro and in vivo enabled by synthetic nanoparticle codelivery of Cas 9 mRNA and sgRNA. Angew. Chem. Int. Ed. 56(4), 1059-1063 (2017)

62. Alsaiari, S.K., Patil, S., Alyami, M., Alamoudi, K.O., Aleisa, F.A., Merzaban, J.S., Li, M., Khashab, N.M.: Endosomal escape and delivery of CRISPR/Cas9 genome editing machinery enabled by nanoscale zeolitic imidazolate framework. J. Am. Chem. Soc. 140(1), 143-146 (2017)

63. Qiu, M., Glass, Z., Xu, Q.: Nonviral Nanoparticles for CRISPR-based genome editing: is it just a simple adaption of what have been developed for nucleic acid delivery? Biomacromol 20(9), 3333-3339 (2019)

64. Zhang, Y., Jiang, Q., Bi, B., Xu, L., Liu, J., Zhuo, R., Jiang, $\mathrm{X}$.: A bioreducible supramolecular nanoparticle gene delivery system based on cyclodextrin-conjugated polyaspartamide and adamantyl-terminated polyethylenimine. J Mater Chem B. 6(5), 797-808 (2018)

65. Wareing, N., Szymanski, K., Akkaraju, G.R., Loni, A., Canham, L.T., Gonzalez-Rodriguez, R., Coffer, J.L.: In vitro gene delivery with large porous silicon nanoparticles fabricated using cost-effective, metal-assisted chemical etching. Small 13(3), 1602739 (2017)

66. Wu, Y., Gu, W., Tang, J., Xu, Z.P.: Devising new lipid-coated calcium phosphate/carbonate hybrid nanoparticles for controlled release in endosomes for efficient gene delivery. J Mater Chem B. 5(34), 7194-7203 (2017)
67. Sokolova, V.V., Radtke, I., Heumann, R., Epple, M.: Effective transfection of cells with multi-shell calcium phosphate-DNA nanoparticles. Biomaterials 27(16), 3147-3153 (2006)

68. Kato, S., Anderson, R., Camerini-Otero, R.: Foreign DNA introduced by calcium phosphate is integrated into repetitive DNA elements of the mouse L cell genome. Mol. Cell. Biol. 6(5), 1787-1795 (1986)

69. Huang, X., Andina, D., Ge, J., Labarre, A., Leroux, J.-C., Castagner, B.: Characterization of calcium phosphate nanoparticles based on a PEGylated chelator for gene delivery. ACS Appl. Mater. Interfaces. 9(12), 10435-10445 (2017)

70. Shekhar, S., Roy, A., Hong, D., Kumta, P.N.: Nanostructured silicate substituted calcium phosphate (NanoSiCaPs) nanoparticles-Efficient calcium phosphate based non-viral gene delivery systems. Mater Sci Eng C. 69, 486-495 (2016)

71. Chernousova, S., Epple, M.: Live-cell imaging to compare the transfection and gene silencing efficiency of calcium phosphate nanoparticles and a liposomal transfection agent. Gene Ther. 24(5), 282 (2017)

72. Karthik, K., Dhanuskodi, S., Gobinath, C., Prabukumar, S., Sivaramakrishnan, S.: Dielectric and antibacterial studies of microwave assisted calcium hydroxide nanoparticles. J. Mater. Sci. Mater. Electron. 28(21), 16509-16518 (2017)

73. Rodriguez-Navarro, C., Suzuki, A., Ruiz-Agudo, E.: Alcohol dispersions of calcium hydroxide nanoparticles for stone conservation. Langmuir 29(36), 11457-11470 (2013)

74. Gorbe, M., Bhat, R., Aznar, E., Sancenon, F., Marcos, M.D., Herraiz, F.J., Prohens, J., Venkataraman, A., Martinez-Manez, R.: Rapid biosynthesis of silver nanoparticles using pepino (Solanum muricatum) leaf extract and their cytotoxicity on HeLa cells. Materials 9(5), 325 (2016)

75. Anandalakshmi, K., Venugobal, J., Ramasamy, V.: Characterization of silver nanoparticles by green synthesis method using Pedalium murex leaf extract and their antibacterial activity. Appl. Nanosci. 6(3), 399-408 (2016)

76. Loh, X.J., Lee, T.-C., Dou, Q., Deen, G.R.: Utilising inorganic nanocarriers for gene delivery. Biomater. Sci. 4(1), 70-86 (2016)

77. Blum, A.P., Kammeyer, J.K., Rush, A.M., Callmann, C.E., Hahn, M.E., Gianneschi, N.C.: Stimuli-responsive nanomaterials for biomedical applications. J. Am. Chem. Soc. 137(6), 2140-2154 (2015)

78. Karimi, M., Hesaraki, S., Alizadeh, M., Kazemzadeh, A.: A facile and sustainable method based on deep eutectic solvents toward synthesis of amorphous calcium phosphate nanoparticles: the effect of using various solvents and precursors on physical characteristics. J. Non-Cryst. Solids. 443, 59-64 (2016)

79. Hirano, M., Yokoiwa, Y., Komai, S., Ohtsu, N.: Enhanced calcification of osteoblast-like cells on zirconium through calciumphosphate slurry processing. Appl. Surf. Sci. 478, 567-573 (2019)

80. Gu, X., Tao, Y., Pan, Y., Deng, L., Bao, L., Kong, Y.: DNAinspired electrochemical recognition of tryptophan isomers by electrodeposited chitosan and sulfonated chitosan. Anal. Chem. 87(18), 9481-9486 (2015)

81. He, Z., Liu, J., Qiao, Y., Li, C.M., Tan, T.T.Y.: Architecture engineering of hierarchically porous chitosan/vacuum-stripped graphene scaffold as bioanode for high performance microbial fuel cell. Nano Lett. 12(9), 4738-4741 (2012)

82. Che, A.-F., Liu, Z.-M., Huang, X.-J., Wang, Z.-G., Xu, Z.-K.: Chitosan-modified poly (acrylonitrile-co-acrylic acid) nanofibrous membranes for the immobilization of concanavalin A. Biomacromol 9(12), 3397-3403 (2008)

83. Khan, M.D., Ahn, J.W., Nam, G.: Environmental benign synthesis, characterization and mechanism studies of green calcium hydroxide nano-plates derived from waste oyster shells. J. Environ. Manag. 223, 947-951 (2018) 
84. Tang, J., Li, L., Howard, C.B., Mahler, S.M., Huang, L., Xu, Z.P.: Preparation of optimized lipid-coated calcium phosphate nanoparticles for enhanced in vitro gene delivery to breast cancer cells. J. Mater. Chem. B. 3(33), 6805-6812 (2015)

85. Park, H., Kim, M.H., Yoon, Y.I., Park, W.H.: One-pot synthesis of injectable methylcellulose hydrogel containing calcium phosphate nanoparticles. Carbohydr. Polym. 157, 775-783 (2017)

86. Loca, D., Sokolova, M., Locs, J., Smirnova, A., Irbe, Z.: Calcium phosphate bone cements for local vancomycin delivery. Mater. Sci. Eng. C. 49, 106-113 (2015)

87. Kulterer, M.R., Reischl, M., Reichel, V.E., Hribernik, S., Wu, M., Köstler, S., Kargl, R., Ribitsch, V.: Nanoprecipitation of cellulose acetate using solvent/nonsolvent mixtures as dispersive media. Colloids Surf. A Physicochem. Eng. Asp. 375(1-3), 23-29 (2011)

88. Liu, T., Zhu, Y., Zhang, X., Zhang, T., Zhang, T., Li, X.: Synthesis and characterization of calcium hydroxide nanoparticles by hydrogen plasma-metal reaction method. Mater. Lett. 64(23), 2575-2577 (2010)

89. Samanta, A., Chanda, D.K., Das, P.S., Ghosh, J., Mukhopadhyay, A.K., Dey, A.: Synthesis of nano calcium hydroxide in aqueous medium. J. Am. Ceram. Soc. 99(3), 787-795 (2016)

90. Karimi, M., Hesaraki, S., Alizadeh, M., Kazemzadeh, A.: Synthesis of calcium phosphate nanoparticles in deep-eutectic choline chloride-urea medium: Investigating the role of synthesis temperature on phase characteristics and physical properties. Ceram. Int. 42(2), 2780-2788 (2016)

91. Keskar, M., Sabatini, C., Cheng, C., Swihart, M.T.: Synthesis and characterization of silver nanoparticle-loaded amorphous calcium phosphate microspheres for dental applications. Nanosc. Adv. 1(2), 627-635 (2019)

92. Correia, L.M., Campelo, N.D.S., Albuquerque, R.D.F., Cavalcante, C.L., Cecilia, J.A., Rodríguez-Castellón, E., Guibal, E., Vieira, R.S.: Calcium/chitosan spheres as catalyst for biodiesel production. Polym. Int. 64(2), 242-249 (2015)

93. Kalliola, S., Repo, E., Srivastava, V., Heiskanen, J.P., Sirviö, J.A., Liimatainen, H., Sillanpää, M.: The $\mathrm{pH}$ sensitive properties of carboxymethyl chitosan nanoparticles cross-linked with calcium ions. Colloids Surf. B: Biointerfaces. 153, 229-236 (2017)

94. Bonengel, S., Prüfert, F., Jelkmann, M., Bernkop-Schnürch, A.: Zeta potential changing phosphorylated nanocomplexes for pDNA delivery. Int. J. Pharm. 504(1-2), 117-124 (2016)

95. Cheng, X., Lee, R.J.: The role of helper lipids in lipid nanoparticles (LNPs) designed for oligonucleotide delivery. Adv. Drug Deliv. Rev. 99, 129-137 (2016)

96. Olton, D., Li, J., Wilson, M.E., Rogers, T., Close, J., Huang, L., Kumta, P.N., Sfeir, C.: Nanostructured calcium phosphates (NanoCaPs) for non-viral gene delivery: influence of the synthesis parameters on transfection efficiency. Biomaterials 28(6), 1267-1279 (2007)

97. Taranejoo, S., Liu, J., Verma, P., Hourigan, K.: A review of the developments of characteristics of PEI derivatives for gene delivery applications. J. Appl. Polym. Sci. 132(25), 42096 (2015)

98. Wu, D., Zhang, Y., Xu, X., Guo, T., Xie, D., Zhu, R., Chen, S., Ramakrishna, S., He, L.: RGD/TAT-functionalized chitosangraft-PEI-PEG gene nanovector for sustained delivery of NT-3 for potential application in neural regeneration. Acta Biomater. 72, 266-277 (2018)

99. Schulze, J., Kuhn, S., Hendrikx, S., Schulz-Siegmund, M., Polte, T., Aigner, A.: Spray-sstems (NiMDS) for gene delivery, comprising polyethylenimine (PEI)-based nanoparticles in a poly (Vinyl Alcohol) Matrix. Small 14(12), 1701810 (2018)

100. Giles, C., MacEwan, T., Nakhwa, S., Smith, D.: Studies in adsorption Part XI A system of classification of solution adsorption isotherms, and its use in diagnosis of adsorption mechanisms and in measurement of specific surface areas of solids. J. Chem. Soc. (Resumed) 786, 3973-3993 (1960)

101. Giles, C.H., Smith, D., Huitson, A.: A general treatment and classification of the solute adsorption isotherm. I. Theoret. J. Colloid Interface Sci. 47(3), 755-765 (1974)

102. Imani, R., Prakash, S., Vali, H., Faghihi, S.: Polyethylene glycol and octa-arginine dual-functionalized nanographene oxide: an optimization for efficient nucleic acid delivery. Biomater. Sci. 6(6), 1636-1650 (2018)

103. Kudsiova, L., Mohammadi, A., Mustapa, M.F.M., Campbell, F., Welser, K., Vlaho, D., Story, H., Barlow, D.J., Tabor, A.B., Hailes, H.C.: Trichain cationic lipids: the potential of their lipoplexes for gene delivery. Biomater. Sci. 7(1), 149-158 (2019)

104. Di Mauro, V., Iafisco, M., Salvarani, N., Vacchiano, M., Carullo, P., Ramírez-Rodríguez, G.B., Patrício, T., Tampieri, A., Miragoli, M., Catalucci, D.: Bioinspired negatively charged calcium phosphate nanocarriers for cardiac delivery of MicroRNAs. Nanomedicine 11(8), 891-906 (2016)

105. Tang, J., Howard, C.B., Mahler, S.M., Thurecht, K.J., Huang, L., Xu, Z.P.: Enhanced delivery of siRNA to triple negative breast cancer cells in vitro and in vivo through functionalizing lipid-coated calcium phosphate nanoparticles with dual target ligands. Nanoscale 10(9), 4258-4266 (2018)

106. Liu, S., Jia, H., Yang, J., Pan, J., Liang, H., Zeng, L., Zhou, H., Chen, J., Guo, T.: Zinc coordination substitute amine: a noncationic platform for efficient and safe gene delivery. ACS Macro Lett. 7(7), 868-874 (2018)

107. Bila, H., Kurisinkal, E.E., Bastings, M.M.: Engineering a stable future for DNA-origami as a biomaterial. Biomater. Sci. 7(2), 532-541 (2019)

108. Austin, M.J., Rosales, A.M.: Tunable biomaterials from synthetic, sequence-controlled polymers. Biomater. Sci. 7(2), 490-505 (2019)

109. Bank, R.A.: Limiting biomaterial fibrosis. Nat. Mater. 18(8), 781 (2019)

110. Ahn, C.H., Chae, S.Y., Bae, Y.H., Kim, S.W.: Biodegradable poly (ethylenimine) for plasmid DNA delivery. J. Control. Release 80(13), 273-282 (2002)

111. Bishop, C.J., Tzeng, S.Y., Green, J.J.: Degradable polymercoated gold nanoparticles for co-delivery of DNA and siRNA. Acta Biomater. 11, 393-403 (2015)

112. Keles, E., Song, Y., Du, D., Dong, W.-J., Lin, Y.: Recent progress in nanomaterials for gene delivery applications. Biomater. Sci. 4(9), 1291-1309 (2016)

113. Kim, J., Kim, H., Kim, W.J.: Single-layered MoS2-PEI-PEG nanocomposite-mediated gene delivery controlled by photo and redox stimuli. Small 12(9), 1184-1192 (2016)

114. Andronikou, N., Lee, W., Neal, M., Zou, Y., La Course, M., du Jeu, X.D.M., Ravinder, N.: Enabling the advancement of non-viral CRISPR-based cell therapy with a new Large-scale electroporation platform. Cytotherapy 22(5), S206 (2020)

115. Rohiwal, S., Dvorakova, N., Klima, J., Vaskovicova, M., Senigl, F., Slouf, M., Pavlova, E., Stepanek, P., Babuka, D., Benes, H.: Polyethylenimine based magnetic nanoparticles mediated non-viral CRISPR/Cas9 system for genome editing. Sci. Rep. 10(1), 1-12 (2020)

116. He, H., Kang, H., Ma, S., Bai, Y., Yang, X.: High adsorption selectivity of $\mathrm{ZnAl}$ layered double hydroxides and the calcined materials toward phosphate. J. Colloid Interface Sci. 343(1), 225-231 (2010)

117. Yu, J., Lu, L., Li, J., Song, P.: Biotemplated hierarchical porous-structure of $\mathrm{ZnAl}-\mathrm{LDH} / \mathrm{ZnCo} 2 \mathrm{O} 4$ composites with enhanced adsorption and photocatalytic performance. RSC Adv. 6(16), 12797-12808 (2016) 
118. Komarneni, S., Kozai, N., Roy, R.: Novel function for anionic clays: selective transition metal cation uptake by diadochy. J. Mater. Chem. 8(6), 1329-1331 (1998)

119. Chen, S., Yang, F., Cao, Z., Yu, C., Wang, S., Zhong, H.: Enhanced photocatalytic activity of molybdenum disulfide by compositing ZnAl-LDH. Colloids Surf. A Physicochem. Eng. Asp. 586, 124140 (2020)
Publisher's Note Springer Nature remains neutral with regard to jurisdictional claims in published maps and institutional affiliations. 